\title{
Risk factors for gallbladder contractility after cholecystolithotomy in elderly high-risk surgical patients
}

\author{
Tao Wang* \\ Hao Luo* \\ Hong-tao Yan* \\ Guo-hu Zhang \\ Wei-hui Liu \\ Li-jun Tang
}

General Surgery Center, Chengdu Military General Hospital, Chengdu, Sichuan, People's Republic of China

*These authors contributed equally to this work
Correspondence: Li-jun Tang; Wei-hui Liu General Surgery Center, Chengdu Military General Hospital, No 270 Rongdu Avenue, Chengdu, Sichuan 610083, People's Republic of China Tel +8628 86570265

Email whitlj I25 I@I63.com; weihuiliu1984@।63.com
This article was published in the following Dove Press journal:

Clinical Interventions in Aging

12 January 2017

Number of times this article has been viewed

Objective: Cholecystolithiasis is a common disease in the elderly patient. The routine therapy is open or laparoscopic cholecystectomy. In the previous study, we designed a minimally invasive cholecystolithotomy based on percutaneous cholecystostomy combined with a choledochoscope (PCCLC) under local anesthesia.

Methods: To investigate the effect of PCCLC on the gallbladder contractility function, PCCLC and laparoscope combined with a choledochoscope were compared in this study.

Results: The preoperational age and American Society of Anesthesiologists (ASA) scores, as well as postoperational lithotrity rate and common biliary duct stone rate in the PCCLC group, were significantly higher than the choledochoscope group. However, the pre- and postoperational gallbladder ejection fraction was not significantly different. Univariable and multivariable logistic regression analyses indicated that the preoperational thickness of gallbladder wall (odds ratio [OR]: $0.540 ; 95 \%$ confidence interval [CI]: $0.317-0.920 ; P=0.023$ ) and lithotrity (OR: $0.150 ; 95 \% \mathrm{CI}: 0.023-0.965 ; P=0.046)$ were risk factors for postoperational gallbladder ejection fraction. The area under receiver operating characteristics curve was $0.714(P=0.016$; 95\% CI: 0.553-0.854).

Conclusion: PCCLC strategy should be carried out cautiously. First, restricted by the diameter of the drainage tube, the PCCLC should be used only for small gallstones in high-risk surgical patients. Second, the usage of lithotrity should be strictly limited to avoid undermining the gallbladder contractility and increasing the risk of secondary common bile duct stones.

Keywords: cholecystolithotomy, lithotrity, thickness of gallbladder wall, GBEF, gallbladder motility

\section{Introduction}

The prevalence of cholecystolithiasis in adults is $\sim 10 \%$, especially higher in the aged. The history of surgical treatment of cholecystolithiasis has been more than 100 years. In 1987, the first case of laparoscopic cholecystectomy (LC) was carried out. As the invasive surgery technique progressing, LC expands the subject range of invasive surgical management of gallstone. However, with the recognition of the importance of gallbladder function, more and more patients are aware of the consequence of LC, such as biliary injury and dyspepsia problem. Some novel strategies to remove the stone and preserve gallbladder are adopted. Tan et al introduces a novel strategy using laparoscope combined with choledochoscope (LSC) to extract the gallstones. ${ }^{1}$ Kim et al report an original fluoroscopy-guided percutaneous gallstones removal. ${ }^{2}$ Some other methods include oral dissolution therapy and extracorporeal shockwave lithotripsy (ESWL). ${ }^{3,4}$ 
In a previous study, we put forward an idea of invasive percutaneous cholecystolithotomy (PCCL) methods based on percutaneous cholecystostomy combined with choledochoscope (PCCLC) under local anesthesia. ${ }^{5}$ No matter which methods are adopted, the recurrence rate must first be taken into consideration. Wang et $\mathrm{al}^{6,7}$ propose the idea that the formation of gallstones is a systemic and genetic procedure with dysmetabolism of cholesterol and biliary bile acids as well as dysfunctional gallbladder motility accompanied with the hypersecretion of mucins. Meanwhile, the recurrence rate of gallstones in patients with poor gallbladder function before PCCL was significantly higher than in those without this factor. ${ }^{8-10}$ To investigate the long-term recurrence rate post operation, the change in gallbladder function needs to be demonstrated first.

In this study, the gallbladder contractility functions between two different invasive strategies were compared.

\section{Patients and methods}

\section{General information}

From January 2010 to December 2014, consecutive 48 patients, who were diagnosed as cholecystolithiasis by ultrasound after admission, were treated with cholecystolithotomy. The patients were grouped into the PCCLC group and the LSC group according to the disparity of surgical methods. All patients were willing to undergo the minimally invasive surgery. The surgical plans were discussed and approved by the Chengdu Military Hospital Ethics Committee. The Declaration of Helsinki for Medical Research has been strictly adhered to. Written informed consent was obtained from all patients to participate in this study and for the publication of the associated images.

\section{Materials and equipment}

PCCL in the PCCLC group was performed using Philips iu22 ultrasound system (Philips, Amsterdam, the Netherlands),
Pigtail Drainage Catheter Set (7-Fr and 16-Fr; Bioteque, Taipei, People's Republic of China), and Amplatz Dilator Set (12-22-Fr; Cook, Bloomington, IN, USA). Retrieval or pulverization of the gallstone was performed using Trapezoid RX Wire-guided Retrieval Basket (Boston Scientific, Boston, MA, USA) and Pentax EPM-3500/ECN-1530 (Pentax, Tokyo, Japan) choledochoscope system under local anesthesia. The LSC group adopted Olympus HD EndoEYE (Olympus, Tokyo, Japan) and Trapezoid RX Wire-guided Retrieval Basket (Boston Scientific) to execute the surgery under general anesthesia.

\section{Methods}

\section{The procedures of PCCLC}

The PCCLC procedures were performed as described before. ${ }^{5}$ In brief, a primary 7-Fr pigtail drainage catheter was percutaneously and trans-hepatically inserted into the neck of the gallbladder under ultrasound guidance using a single trocar technique. The secondary $16-\mathrm{Fr}$ catheter was percutaneously non-transhepatically inserted at the bottom of the gallbladder using the same method (Figure 1A). The secondary catheter was used as the choledochoscope working tract. After the secondary catheter was dilated into $22-\mathrm{Fr}$, a 20-Fr sheath was carried into the gallbladder cavity. The choledochoscope was inserted into the gallbladder along with the 20-Fr sheath to grasp stones using the stone extractor or pulverize the stones (Figure 1B).

\section{The procedures of LSC}

The LSC procedures were performed under general anesthesia. The locations of the puncture points and the surgical methods were similar with regular LC. Then a small incision was made at the bottom of the gallbladder according to the size of the stone. After the bile was suctioned, the choledochoscope was introduced into the gallbladder. The rest procedures of
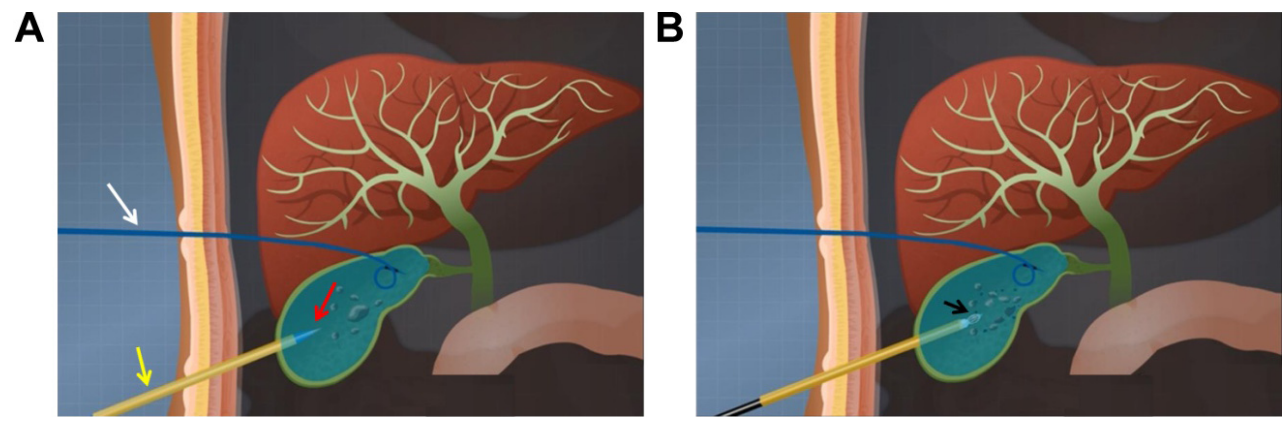

Figure I The schematic representation of percutaneous cholecystostomy combined with choledochoscope procedures.

Notes: (A) Ultrasound-guided percutaneous cholecystostomy. The white arrow indicates the percutaneous transhepatic puncture route. The yellow arrow shows the sheath combined with a puncture needle. The red arrow indicates puncture needles getting into the colecyst. (B) Manipulation of cholecystolithotrity using a choledochoscope. The black arrow indicates the cholecystolithotrity procedures using a choledochoscope of retrieval basket. 

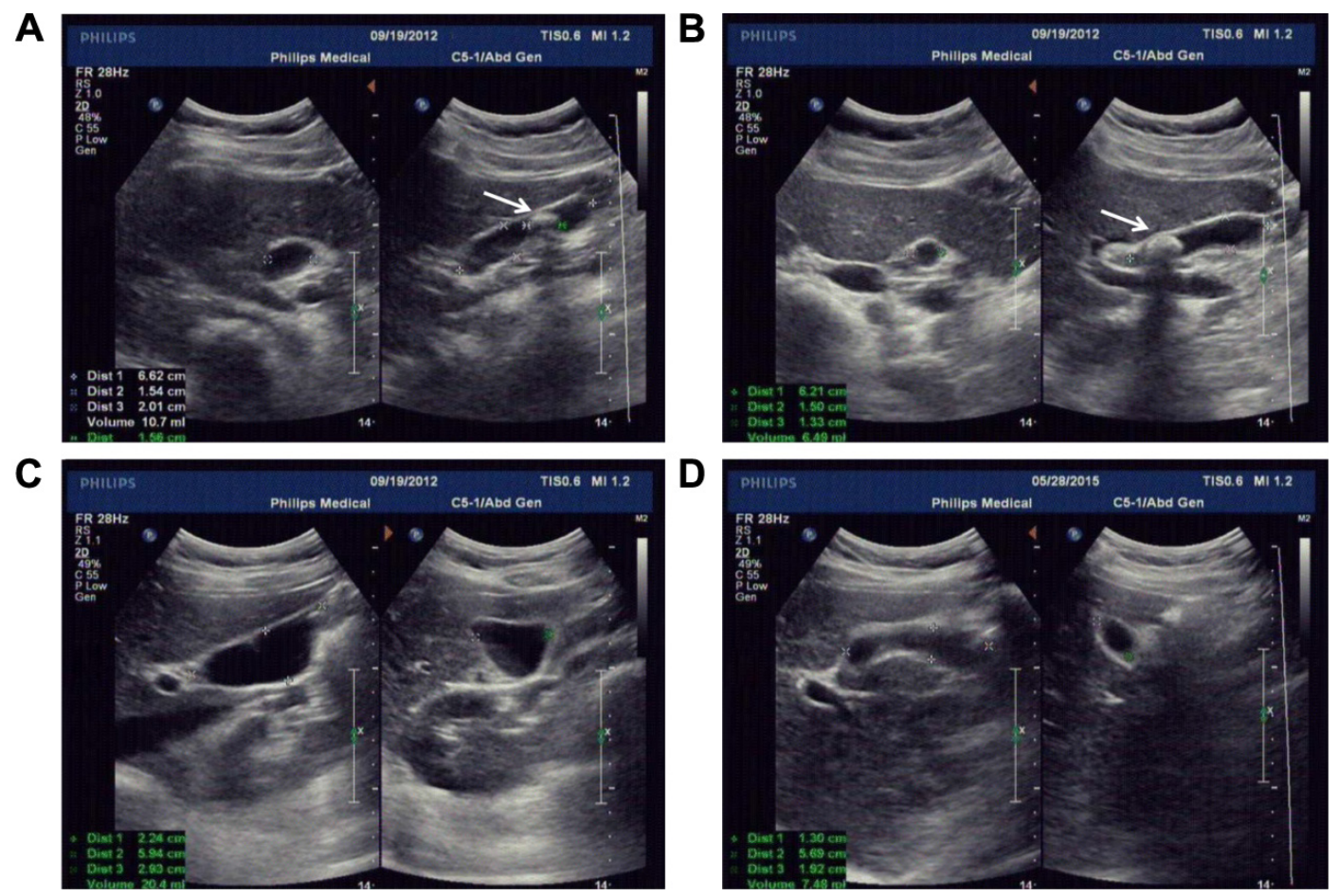

Figure 2 A significant alleviation of GBEF before and after surgery.

Notes: (A, B) Preoperational ultrasound results. Preoperational ultrasound found a single stone with a diameter of $15.6 \mathrm{~mm}$. The white arrow shows the single stone. Preoperational GBEF was 39\%. (C, D) Postoperational ultrasound results. Postoperational ultrasound found no stone residual. Postoperational GBEF was $63 \%$.

Abbreviation: GBEF, gallbladder ejection fraction.

pulverization or retrieval of the gallstone were similar with PCCLC. At last, the incision of the gallbladder and the abdomen was closed using a running suture. To avoid bile leakage, a 7-Fr drainage tube was routinely placed.

\section{Follow-up}

After the surgery, antibiotics and an anti-hemorrhagics were given to the patients in the traditional manner. While this procedure was minimally invasive, the patients could be monitored in a regular ward or in the intensive care unit if necessary. The secondary catheter of PCCLC was removed after the ultrasound confirmed that there were no residual stones. The primary catheter in the PCCLC group and the drainage tube in the LSC group were reserved for drainage after the patient was discharged, and it was extracted in a clinic service setting after the sinus returned to normal. To avoid relapse, the patients were prescribed taurocholate ursodeoxycholic acid when they were discharged. After all the drainage tubes were removed, the gallbladder contractility function was detected.

\section{Gallbladder contractility function}

Gallbladder contractility function was represented by fasting gallbladder volume (FGBV), postprandial gallbladder volume (PGBV), and gallbladder ejection fraction (GBEF), which were calculated by ultrasonography. Gallbladder volume (GBV) was determined by the formula: GBV $=\pi / 6 \times(L \times W \times H)$, with dimension sagittal length $(L)$, width $(W)$, and axial height $(H)$. GBEF was determined using the following formula: GBEF $(\%)=(\mathrm{FGBV}-\mathrm{PGBV}) /$ $(\mathrm{FGBV}) \times 100 \%$. PGBV was the volume at 30 minutes after a high-fat diet (Figures 2A-D and 3A-D). Ultrasonographic studies were performed by the same investigator.

\section{Statistical analysis}

Statistical analysis was performed using Statistical Package for the Social Sciences (SPSS) Version 19.0 (SPSS, Chicago, IL, USA). Continuous data were presented as the mean \pm standard deviation (SD) and evaluated using Fisher's exact $t$-test or Mann-Whitney $U$ test. Categorical data were described with frequency counts and assessed using the $\chi^{2}$ test. Two-tailed $P$-values $<0.05$ were considered to indicate statistical significance.

\section{Results}

\section{Patients}

A total of 48 cholecystolithiasis cases were included: the PCCLC group included 17 (31.42\%) cases and the LSC group included $31(64.58 \%)$ cases. The characteristics of the 
A

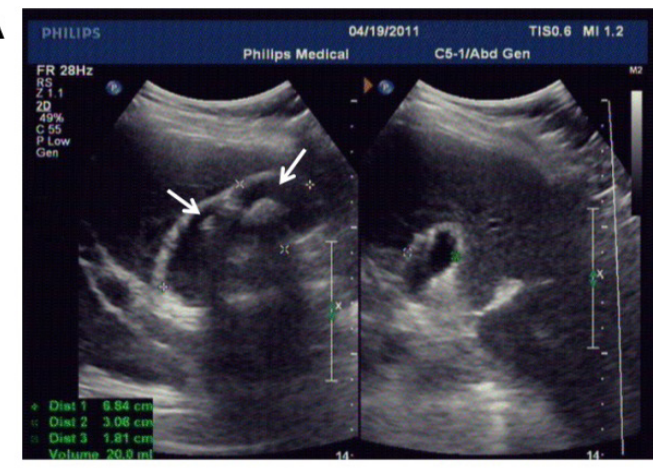

C

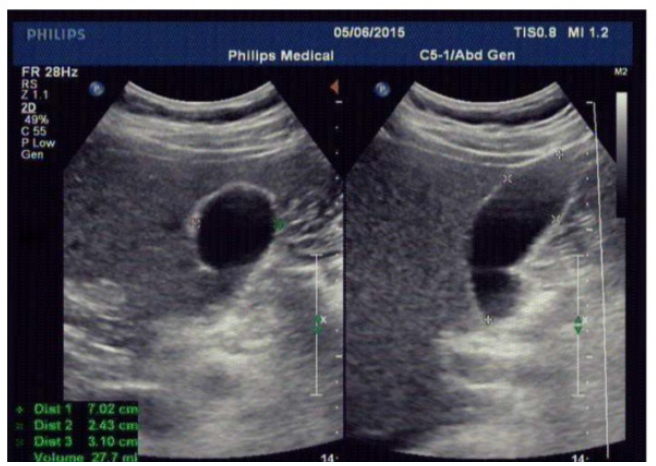

B

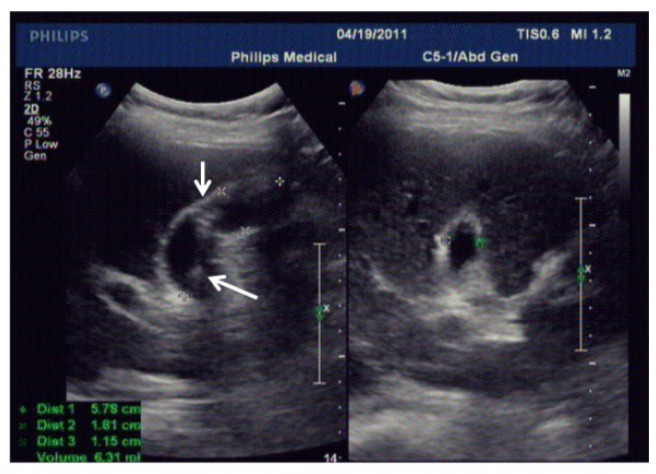

D

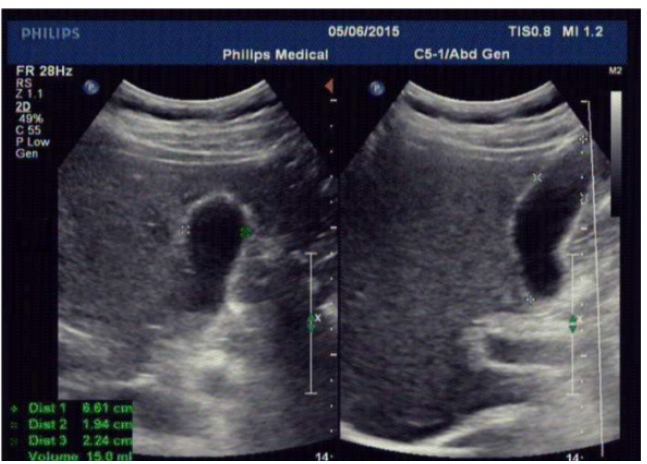

Figure 3 A significant deterioration of GBEF before and after surgery.

Notes: (A, B) Preoperational ultrasound results. Preoperational ultrasound found multiple stones with the largest diameter of $26 \mathrm{~mm}$. The white arrow shows the single stone. Preoperational GBEF was $68 \%$. This patient adopted lithotrity because of the large diameter of stones. (C, D) Postoperational ultrasound results. Postoperational ultrasound found no stone residual. Postoperational GBEF was $46 \%$.

Abbreviation: GBEF, gallbladder ejection fraction.

patients are shown in Table 1. The average age of patients in the PCCLC group was $41.2 \pm 13.7$ versus $33.9 \pm 7.7$ years in the LSC group. The preoperational GBEF was not significantly different between the two groups. The American Society of Anesthesiologists (ASA) scores in both groups were $3.1 \pm 0.6$ and $2.7 \pm 0.4$, respectively. The higher age $(P=0.018$; Table 1) and ASA scores ( $P=0.008$; Table 1$)$ in the PCCLC group than that in the LSC group indicated that patients in the PCCLC group might face higher surgical risks.

\section{Characteristics of complications and outcomes of patients}

Table 2 delineated the therapeutic outcomes of the three groups. Due to the oversize of gallstones, a total number of 10 patients received the lithotrity treatment during the operation. A significantly higher lithotrity rate in the PCCLC group ( 7 cases, $41.12 \%$ ) than that in the LSC group ( 3 cases, $9.68 \% ; P=0.022$; Table 2) was observed, as well as higher incidence of choledocholithiasis $(23.53 \%$ versus $3.23 \%$; $P=0.047$; Table 2). With lots of fragment stones being generated, it may result in the secondary common bile duct (CBD) stones. Nevertheless, the admission day was shorter in the PCCLC group ( $4.5 \pm 0.8$ versus $4.9 \pm 0.4 ; P=0.018$; Table 2 ).
No significant differences were found between the two groups in postoperational GBEF, the postoperational thickness of gallbladder wall, duration of the drainage tube, quality of life (QOL) and complications, such as bleeding and bile leakage.

Interestingly, we found that the number of patients whose GBEF was $>50 \%$ had increased after surgery in both groups. However, compared with GBEF before surgery, there was no significant difference $(P=0.732$ in the PCLC group and $P=0.611$ in the LSC group; Table 3).

To analyze which clinical factors played a crucial role in postoperational GBEF alleviation, patients were grouped according to whether their postoperational GBEF is more than $50 \%$. Then, univariable and multivariable logistic regression analyses were conducted in the next section.

\section{Logistic regression analysis}

Table 4 showed the factors indicative of GBEF alleviation after surgery. These variables were significantly different between GBEF alleviation and non-alleviation after surgery: thickness of gallbladder wall (odds ratio [OR]: $0.541 ; 95 \%$ confidence interval [CI]: $0.336-0.872 ; P=0.012$; Table 4) and lithotrity (OR: 0.146; 95\% CI: 0.027-0.785; 
Table I Baseline characteristics of all patients in each group

\begin{tabular}{|c|c|c|c|}
\hline Characteristics & $\begin{array}{l}\text { PCCLC } \\
(n=17)\end{array}$ & $\begin{array}{l}\text { LSC } \\
(n=31)\end{array}$ & $P$-value \\
\hline Gender & & & 0.761 \\
\hline Male & 7 & 11 & \\
\hline Female & 10 & 20 & \\
\hline Age (years) & $41.2 \pm 13.7$ & $33.9 \pm 7.7$ & 0.018 \\
\hline Number of stones & & & 1.000 \\
\hline Single & 2 & 3 & \\
\hline Multiple & 15 & 28 & \\
\hline Maximum stone diameter $(\mathrm{mm})$ & $|4| \pm 0.9$. & $13.7 \pm 0.6$ & 0.668 \\
\hline Preoperational GBEF (\%) & & & 0.769 \\
\hline$\geq 50$ & 8 & 13 & \\
\hline$<50$ & 9 & 18 & \\
\hline Thickness of cholecyst wall (mm) & $3.5 \pm 0.4$ & $3.8 \pm 0.6$ & 0.681 \\
\hline ASA score & $3.1 \pm 0.6$ & $2.7 \pm 0.4$ & 0.008 \\
\hline Combined with liver disease & & & 0.235 \\
\hline Yes & 5 & 5 & \\
\hline No & 12 & 26 & \\
\hline \multicolumn{4}{|l|}{ Laboratory parameters } \\
\hline Cholesterol (mmol/L) & $4.3 \pm 1.1$ & $4.8 \pm 0.8$ & 0.077 \\
\hline Total bilirubin $(\mu \mathrm{mol} / \mathrm{L})$ & $16.7 \pm 2.3$ & $|5.8 \pm 3|$. & 0.300 \\
\hline AST (U/L) & $35.3 \pm 11.7$ & $30.9 \pm 6.9$ & 0.930 \\
\hline ALT (U/L) & $33.1 \pm 9.3$ & $38.7 \pm 10.4$ & 0.071 \\
\hline GGT (U/L) & $49.5 \pm 14.9$ & $40.6 \pm 15.3$ & 0.058 \\
\hline ALP (U/L) & $77.1 \pm 20.9$ & $71.2 \pm 17.4$ & 0.301 \\
\hline Leukocyte (109/L) & $8.6 \pm 1.1$ & $8.1 \pm 0.8$ & 0.077 \\
\hline
\end{tabular}

Note: Data presented as mean \pm standard deviation or $\mathrm{n}$.

Abbreviations: ALP, alkaline phosphatase; ALT, alanine aminotransferase; ASA, American Society of Anesthesiologists; AST, aspartate aminotransferase; GBEF, gallbladder ejection fraction; GGT, gamma-glutamyl transferase; LSC, laparoscope combined with choledochoscope; PCCLC, percutaneous cholecystostomy combined with choledochoscope.

Table 2 Characteristics of complications and outcomes of patients

\begin{tabular}{llll}
\hline Characteristics & PCCLC & LSC & P-value \\
\hline $\begin{array}{l}\text { Lithotrity } \\
\quad \text { Yes }\end{array}$ & 7 & 3 & 0.022 \\
$\quad$ No & 10 & 28 & \\
$\begin{array}{l}\text { Postoperational GBEF (\%) } \\
\quad \geq 50\end{array}$ & 10 & 16 & 0.765 \\
$\quad<50$ & 7 & 15 & \\
Thickness of cholecyst wall (mm) & $2.9 \pm 0.3$ & $3.1 \pm 0.5$ & 0.131 \\
$\begin{array}{l}\text { Bleeding } \\
\quad \text { Yes }\end{array}$ & 1 & 2 & 1.000 \\
$\quad$ No & 16 & 29 & \\
Bile leakage & & & 0.686 \\
$\quad$ Yes & 3 & 4 & \\
$\quad$ No & 14 & 27 & \\
CBD stone/EST & & & 0.047 \\
$\quad$ Yes & 4 & 1 & \\
$\quad$ No & 13 & 30 & \\
Duration of drainage tube (days) & $35.9 \pm 7.6$ & $31.8 \pm 9.1$ & 0.083 \\
Admission day & $4.5 \pm 0.8$ & $4.9 \pm 0.4$ & 0.018 \\
QOL & $4.7 \pm 0.8$ & $4.3 \pm 0.7$ & 0.078 \\
Follow-up time (months) & $29.1 \pm 7.0$ & $33.6 \pm 9.8$ & 0.102 \\
\hline
\end{tabular}

Note: Data presented as mean \pm standard deviation or $n$.

Abbreviations: CBD, common bile duct; EST, endoscopic sphincterotomy; GBEF, gallbladder ejection fraction; LSC, laparoscope combined with choledochoscope; PCCLC, percutaneous cholecystostomy combined with choledochoscope; QOL, quality of life.
Table 3 Pre- and postoperational GBEF in each group

\begin{tabular}{llll}
\hline GBEF & $\geq \mathbf{5 0 \%}$ & $<\mathbf{5 0 \%}$ & $P$-value \\
\hline PCCLC & & & 0.732 \\
$\quad$ Preoperational & 8 & 9 & \\
Postoperational & 10 & 7 & 0.611 \\
LSC & 13 & 18 & \\
Preoperational & 16 & 15 & \\
Postoperational & 16 & & \\
\hline
\end{tabular}

Abbreviations: GBEF, gallbladder ejection fraction; LSC, laparoscope combined with choledochoscope; PCCLC, percutaneous cholecystostomy combined with choledochoscope.

$P=0.025$; Table 4). These factors were described as potential predictors for GBEF alleviation after surgery and were analyzed as variables in the multivariable logistic regression model.

In the multivariable logistic regression analysis, thickness of gallbladder wall (OR: $0.540 ; 95 \% \mathrm{CI}$ : $0.317-0.920 ; P=0.023$; Table 5 ) and lithotrity (OR: 0.150 ; 95\% CI: $0.023-0.965 ; P=0.046$; Table 5) were found to be significantly different between GBEF alleviation and nonalleviation after surgery and were, therefore, identified as risk factors.

For further assessment of the thickness of the gallbladder wall to the GBEF, the area under the curve (AUC) was adopted. The area under the receiver operating characteristic curve (ROC) was $0.714(P=0.016 ; 95 \% \mathrm{CI}$ : 0.553-0.854; Figure 4). It seemed that patients with a thicker gallbladder wall might deserve a worse GBEF alleviation after surgery. In many cases, the thickness of the gallbladder wall was correlated with the inflammatory severity of the gallbladder. ${ }^{11,12}$

Table 4 Univariable logistic regression analysis of postoperational GBEF

\begin{tabular}{|c|c|c|c|c|}
\hline \multirow[t]{2}{*}{ Variables } & \multirow[t]{2}{*}{ OR } & \multicolumn{2}{|l|}{$95 \% \mathrm{Cl}$} & \multirow[t]{2}{*}{$P$-value } \\
\hline & & Lower & Upper & \\
\hline Age & 0.987 & 0.955 & 1.020 & 0.431 \\
\hline Number of stones & 0.857 & 0.275 & 2.672 & 0.790 \\
\hline Maximum stone diameter & 1.009 & 0.921 & 1.130 & 0.699 \\
\hline Thickness of the cholecyst wall & $0.54 I$ & 0.336 & 0.872 & 0.012 \\
\hline Cholesterol & 1.226 & 0.942 & 1.597 & 0.130 \\
\hline Total bilirubin & 1.037 & 0.988 & 1.087 & 0.143 \\
\hline AST & $1.04 \mid$ & 0.998 & 1.085 & 0.061 \\
\hline ALT & 1.019 & 0.990 & 1.048 & 0.209 \\
\hline GGT & 1.002 & 0.974 & 1.030 & 0.896 \\
\hline ALP & 0.999 & 0.887 & 1.010 & 0.820 \\
\hline Leukocyte (109/L) & 0.897 & 0.711 & 1.132 & 0.361 \\
\hline Lithotrity & 0.146 & 0.027 & 0.785 & 0.025 \\
\hline Follow-up time & 0.974 & 0.889 & I.067 & 0.570 \\
\hline
\end{tabular}

Abbreviations: ALP, alkaline phosphatase; ALT, alanine aminotransferase; AST, aspartate aminotransferase; $\mathrm{Cl}$, confidence interval; GBEF, gallbladder ejection fraction; GGT, gamma-glutamyl transferase; OR, odds ratio. 
Table 5 Multivariable logistic regression analysis of postoperational GBEF

\begin{tabular}{lllll}
\hline Variables & OR & \multicolumn{2}{c}{$\mathbf{9 5 \%} \mathbf{C l}$} & P-value \\
\cline { 3 - 4 } & & Lower & Upper & \\
\hline Thickness of the cholecyst wall & 0.540 & 0.317 & 0.920 & 0.023 \\
Lithotrity & 0.150 & 0.023 & 0.965 & 0.046 \\
Constant & & & & 0.010 \\
\hline
\end{tabular}

Abbreviations: $\mathrm{Cl}$, confidence interval; $\mathrm{GBEF}$, gallbladder ejection fraction; $\mathrm{OR}$, odds ratio.

\section{Discussion}

In recent years, gallstones have turned into one of the most common diseases, especially in older patients. With minimally invasive surgery equipment and surgical technique being ameliorated, LC has taken over from open cholecystectomy (OC) and has been placed at the top of the patients' priority list. However, neither OC nor LC is able to apply to those older patients with high surgical risk, who might not be able to tolerate the anesthesia either. Age and ASA scores may be the two insurmountable barriers. In an attempt to conquer these two barriers, we have introduced a novel method based on ultrasound-guided double-tract percutaneous cholecystostomy and choledochoscope cholecystolithotomy (also called PCCLC), which is conducted totally under local anesthesia. ${ }^{5}$ Compared with traditional LSC in this study, it is demonstrated that PCCLC can be safely applied to older people with high ASA scores. Meanwhile,

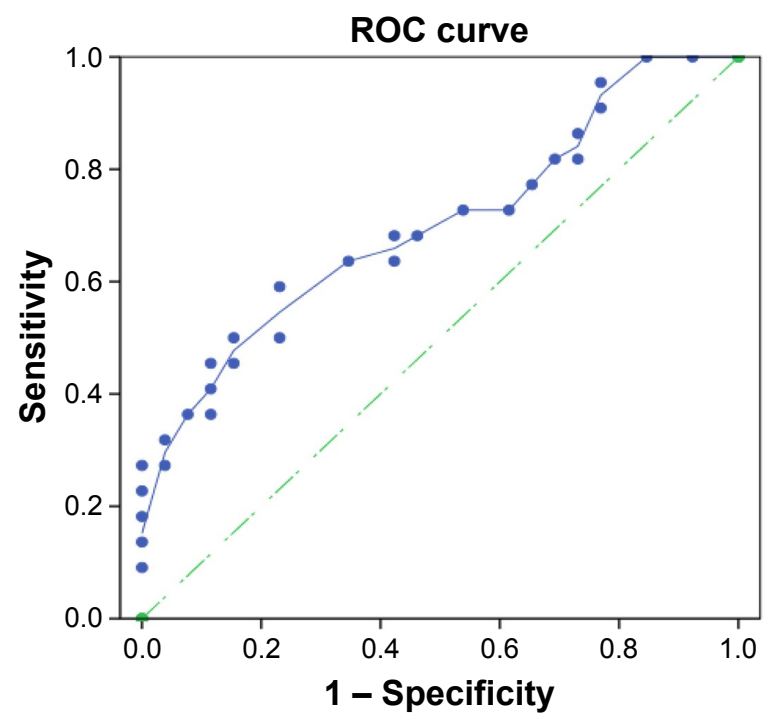

Figure $4 \mathrm{ROC}$ analysis of the gallbladder wall in predicting the postoperational gallbladder contractility.

Notes: The preoperational thickness of the gallbladder wall presented discrimination with an area under the ROC curve of 0.714 ( $P=0.016,95 \%$ confidence interval: $0.553-0.854)$. The green line represents the reference line. Every blue dot represents a predictive result.

Abbreviation: ROC, receiver operating characteristic curve. the admission day after PCCLC is shortened significantly. Although PCCLC may result in additional lithotrity and a higher incidence of secondary CBD stone and endoscopic sphincterotomy (EST; Figure 5A-D), other PCCLC-related complications such as bleeding and bile leakage, postoperational GBEF, duration of the drainage tube, and QOL are similar to LSC.

The application of lithotrity and lithotomy are still controversial due to the possibility of gallstone relapse. It is reported that the recurrence rate of gallstones in patients with poor gallbladder function before PCCL was significantly higher than in those without this factor. ${ }^{8-10}$ Although we find that both postoperational GBEFs are slightly elevated (from 21/48 to $26 / 48$ ) compared with preoperational GBEF, there is no statistical difference between the two groups.

To investigate which factors have played the crucial role in the alleviation of GBEF, the results of this study indicate that preoperational thickness of the gallbladder wall is the independent risk factor for the poor GBEF. The thickness of the gallbladder wall plays an increasingly important role in gallbladder diseases diagnosis. ${ }^{13}$ Not only can the thickness of the gallbladder wall be correlated with acute cholecystitis but it also is able to present chronic cholecystitis. Referring to acute cholecystitis, Zenobii et a ${ }^{14}$ indicate that gallbladder wall thickening can represent the acute inflammatory conditions. In addition, gallbladder wall edema is found to be a predictive factor of severe acute cholecystitis. ${ }^{15}$ When it comes to chronic cholecystitis, patients with symptomatic chronic calculous cholecystitis not only have gallstones but also histopathological evidence of chronic inflammation of the gallbladder wall, who may also suffer from a functional abnormality, such as poor contractility. ${ }^{16,17}$ In our research, those elderly patients are suffering from chronic cholecystitis accompanied with a long course of the disease, which can dramatically affect the gallbladder contractility. We also find that the preoperational thickness of the gallbladder wall is the independent risk factor for the poor postoperational GBEF. The thickness of gallbladder wall $>3 \mathrm{~mm}$ is proved to be coincidence with the inflammatory severity of gallbladder. ${ }^{18}$ In addition, in a novel preoperative clinical scoring system for acute cholecystitis, a gallbladder wall thickness of $>4 \mathrm{~mm}$ is correlated significantly with high scores. ${ }^{19}$ In this study, we find that the preoperational thickness of gallbladder wall of $3.5 \mathrm{~mm}$ is the cutoff point for the poorer and better postoperational GBEF. In liver cirrhosis patients, Loreno et $\mathrm{al}^{20}$ demonstrate that structural changes of the gallbladder wall could induce wall thickening and also affect gallbladder contractility. On the basis of all the 
A

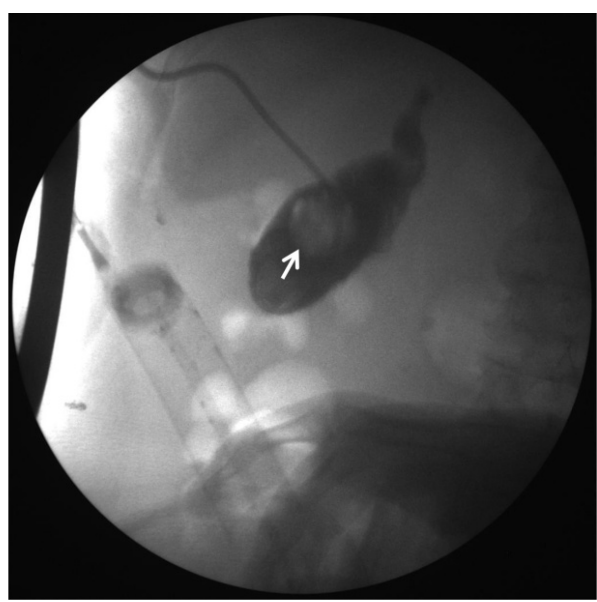

C

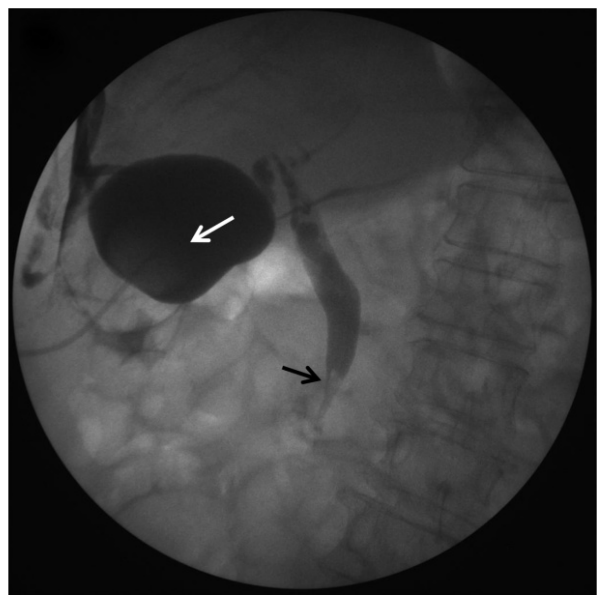

B

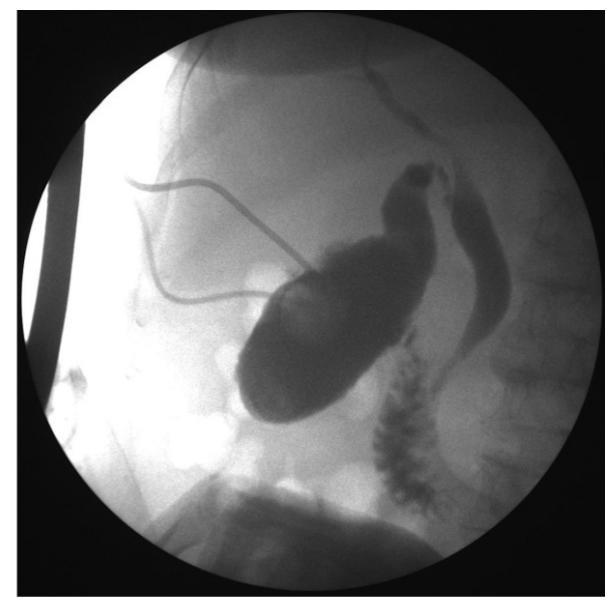

D

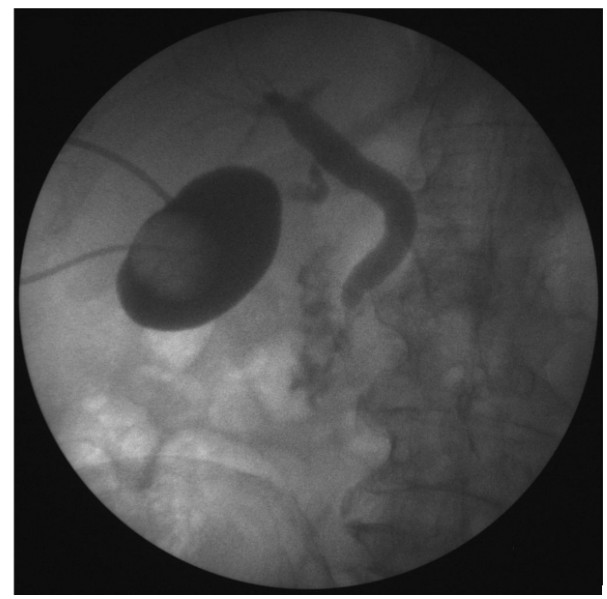

Figure 5 Postoperational cholecystography results.

Notes: (A, B) Postoperational cholecystography results. Postoperational cholecystography found no stone residual in the gallbladder. The white arrow shows the tube with a water balloon. The black arrow shows the suspicious stone. (C, D) Other postoperational cholecystography results. Preoperational endoscopic retrograde cholangiopancreatography did not obtain any positive findings. However, postoperational cholecystography found a suspicious stone in common bile duct but no residual stone in the gallbladder. Postoperational endoscopic sphincterotomy solved that complication.

findings of other research groups and our group, no matter which surgical method is adopted, LC, or PCCLC, or LSC, the preoperational gallbladder wall thickness should be taken into account seriously.

As to lithotrity, an enormous emphasis has been shifted toward gallstone patients who are treated by ESWL. However, Cesmeli et $\mathrm{al}^{21}$ report that there is a significant association of stone recurrence with a number of lithotrity sessions and estrogen intake in ESWL patients. However, the underlying reasons need to be further illustrated. Both Tsumita et $\mathrm{al}^{22}$ and Venneman et $\mathrm{al}^{23}$ give a clue that the probability of stone recurrence is significantly higher in patients with poor gallbladder contractility than in those with good contractility. Ochi et $\mathrm{al}^{24}$ provide a link that the rate of impaired gallbladder contractility was higher in ESWL patients with recurrence when compared with those with no recurrence. Our research gives another link that lithotrity may result in impaired gallbladder contractility, which functions as a bridge between lithotrity and stone recurrence. With lots of fragment stones being generated, it may result in the secondary CBD stones. Hence, lithotrity must be used on the condition that there are no other alternatives.

Although our PCCLC strategy is performed under local anesthesia, it should be carried out cautiously. First of all, being restricted by the diameter of the drainage tube, the PCCLC strategy should be used only for the management of small gallstones in high-risk surgical patients, who are not able to tolerate anesthesia. It also can reduce the chance of lithotrity. Second, the usage of lithotrity should be strictly limited to avoid undermining the gallbladder contractility. With lots of fragmental stones being generated, lithotrity may put the patient at a high risk of unexpected secondary CBD stones.

\section{Acknowledgments}

The authors thank Dr Qi Chen and Hui Zhang who are excellent physicians, and the authors thank them for their 
ultrasound guidance. The authors also thank practiced choledochoscope physicians Dr Bing-yin Zhang, Dan-qing Liu, and Shang-qin Huang for their valuable contribution. They also thank Jiongran Medical Art Studio for the schematic of PCCLC procedures.

\section{Disclosure}

The authors report no conflicts of interest in this work.

\section{References}

1. Tan YY, Zhao G, Wang D, Wang JM, Tang JR, Ji ZL. A new strategy of minimally invasive surgery for cholecystolithiasis: calculi removal and gallbladder preservation. Dig Surg. 2013;30(4-6):466-471.

2. Kim YH, Kim YJ, Shin TB. Fluoroscopy-guided percutaneous gallstone removal using a 12-Fr sheath in high-risk surgical patients with acute cholecystitis. Korean J Radiol. 2011;12(2):210-215.

3. Rabenstein T, Radespiel-Troger M, Hopfner L, et al. Ten years experience with piezoelectric extracorporeal shockwave lithotripsy of gallbladder stones. Eur J Gastroenterol Hepatol. 2005;17(6):629-639.

4. Tazuma S, Nishioka $\mathrm{T}$, Ochi $\mathrm{H}$, et al. Impaired gallbladder mucosal function in aged gallstone patients suppresses gallstone recurrence after successful extracorporeal shockwave lithotripsy. J Gastroenterol Hepatol. 2003;18(2):157-161.

5. Wang T, Chen T, Zou S, et al. Ultrasound-guided double-tract percutaneous cholecystostomy combined with a choledochoscope for performing cholecystolithotomies in high-risk surgical patients. Surg Endosc. 2014;28(7):2236-2242.

6. Wang $\mathrm{HH}$, Portincasa $\mathrm{P}$, de Bari $\mathrm{O}$, et al. Prevention of cholesterol gallstones by inhibiting hepatic biosynthesis and intestinal absorption of cholesterol. Eur J Clin Invest. 2013;43(4):413-426.

7. Wang HH, Portincasa $\mathrm{P}$, Afdhal NH, Wang DQ. Lith genes and genetic analysis of cholesterol gallstone formation. Gastroenterol Clin North Am. 2010;39(2):185-207.

8. Zou YP, Du JD, Li WM, et al. Gallstone recurrence after successful percutaneous cholecystolithotomy: a 10-year follow-up of 439 cases. Hepatobiliary Pancreat Dis Int. 2007;6(2):199-203.

9. Pazzi P, Petroni ML, Prandini N, et al. Postprandial refilling and turnover: specific gallbladder motor function defects in patients with gallstone recurrence. Eur J Gastroenterol Hepatol. 2000;12(7): 787-794.

10. Petroni ML, Jazrawi RP, Pazzi P, et al. Risk factors for the development of gallstone recurrence following medical dissolution. The BritishItalian Gallstone Study Group. Eur J Gastroenterol Hepatol. 2000; 12(6):695-700.
11. Cwik G, Skoczylas T, Wyroslak-Najs J, Wallner G. The value of percutaneous ultrasound in predicting conversion from laparoscopic to open cholecystectomy due to acute cholecystitis. Surg Endosc. 2013;27(7): 2561-2568.

12. Santos BF, Auyang ED, Hungness ES, et al. Preoperative ultrasound measurements predict the feasibility of gallbladder extraction during transgastric natural orifice translumenal endoscopic surgery cholecystectomy. Surg Endosc. 2011;25(4):1168-1175.

13. Xu JM, Guo LH, Xu HX, et al. Differential diagnosis of gallbladder wall thickening: the usefulness of contrast-enhanced ultrasound. Ultrasound Med Biol. 2014;40(12):2794-2804.

14. Zenobii MF, Accogli E, Domanico A, Arienti V. Update on bedside ultrasound (US) diagnosis of acute cholecystitis (AC). Intern Emerg Med. 2016;11(2):261-264.

15. Borzellino G, Steccanella F, Mantovani W, Genna M. Predictive factors for the diagnosis of severe acute cholecystitis in an emergency setting. Surg Endosc. 2013;27(9):3388-3395.

16. Raymond F, Lepanto L, Rosenthall L, Fried GM. Tc-99m-IDA gallbladder kinetics and response to CCK in chronic cholecystitis. Eur J Nucl Med. 1988;14(7-8):378-381.

17. Ziessman HA. Functional hepatobiliary disease: chronic acalculous gallbladder and chronic acalculous biliary disease. Semin Nucl Med. 2006; 36(2):119-132.

18. Villar J, Summers SM, Menchine MD, Fox JC, Wang R. The absence of gallstones on point-of-care ultrasound rules out acute cholecystitis. J Emerg Med. 2015;49(4):475-480.

19. Ambe PC, Papadakis M, Zirngibl H. A proposal for a preoperative clinical scoring system for acute cholecystitis. J Surg Res. 2016;200(2): 473-479.

20. Loreno M, Travali S, Bucceri AM, Scalisi G, Virgilio C, Brogna A. Ultrasonographic study of gallbladder wall thickness and emptying in cirrhotic patients without gallstones. Gastroenterol Res Pract. 2009; 2009:683040

21. Cesmeli E, Elewaut AE, Kerre T, De Buyzere M, Afschrift M, Elewaut A. Gallstone recurrence after successful shock wave therapy: the magnitude of the problem and the predictive factors. Am J Gastroenterol. 1999; 94(2):474-479.

22. Tsumita R, Sugiura N, Abe A, Ebara M, Saisho H, Tsuchiya Y. Longterm evaluation of extracorporeal shock-wave lithotripsy for cholesterol gallstones. J Gastroenterol Hepatol. 2001;16(1):93-99.

23. Venneman NG, vanBerge-Henegouwen GP, Portincasa P, et al. Absence of apolipoprotein E4 genotype, good gallbladder motility and presence of solitary stones delay rather than prevent gallstone recurrence after extracorporeal shock wave lithotripsy. J Hepatol. 2001;35(1):10-16.

24. Ochi H, Tazuma S, Kajihara T, et al. Factors affecting gallstone recurrence after successful extracorporeal shock wave lithotripsy. $J$ Clin Gastroenterol. 2000;31(3):230-232.
Clinical Interventions in Aging

\section{Publish your work in this journal}

Clinical Interventions in Aging is an international, peer-reviewed journal focusing on evidence-based reports on the value or lack thereof of treatments intended to prevent or delay the onset of maladaptive correlates of aging in human beings. This journal is indexed on PubMed Central, MedLine,
Dovepress

CAS, Scopus and the Elsevier Bibliographic databases. The manuscript management system is completely online and includes a very quick and fair peer-review system, which is all easy to use. Visit http://www.dovepress. com/testimonials.php to read real quotes from published authors. 